\title{
Research on the Influence of Information Technology Application on Education
}

\author{
Dan $\mathrm{Li}^{1, *}$, Dong Wang ${ }^{2}$ \\ ${ }^{1}$ Deyang Radio and TV University, Deyang, Sichuan Province, China \\ ${ }^{2}$ Chengdu Jiuzhi Education Technology Co., Ltd, Chengdu, Sichuan Province, China \\ *Corresponding author. Email:962667406@qq.com
}

\begin{abstract}
Technology and education are the two engines to promote the development and progress of human history. Technology is the core force to promote economic and social development, and education is the engine of human capital. Information technology is the key technology of the third industrial revolution. Using information technology to promote the progress of education has important theoretical and practical significance. Through the research of information technology, this paper tells the following rules: information technology greatly improves the information storage capacity, information technology improves the human ability to analyze and process information, information technology promotes the development of educational resources and sharing across time and space, information technology strengthens the interaction of education. Information technology accelerates the progress and development of education through these aspects above.
\end{abstract}

Keywords: Information technology, Education.

\section{INTRODUCTION}

Reviewing the history of human development, technology and education are the core elements to promote economic and social development and human historical progress. Technology is the core force to promote the development of economic and social development, while education is the engine of human capital. The two complement each other and jointly promote the progress and development of human civilization.

In the history of human society, there have been three industrial revolutions. The steam engine invented by Watt brought the first industrial revolution and opened the era of industrial production. The application of internal combustion engine and electric power gave birth to the second industrial revolution of large-scale production mode. The characteristics of the third industrial revolution are mainly information technology and information manufacturing. The fourth industrial revolution is characterized by intelligent information technology, which is a new industrial form represented by big data and artificial intelligence.

Education appears with the emergence of human beings, and also develops and progresses with the development of human society. The change of social form and the development of media technology have always been the fundamental force to promote educational reform.

How to make information technology and education the two engines of human economic and social progress better coordinate and promote each other is an important topic of this paper. It is of great theoretical and practical significance to explore the impact of information technology on education.

\section{INFORMATION TECHNOLOGY AND ITS APPLICATION}

\subsection{Meaning of Information Technology}

Information technology is the general term of various technologies used to obtain, process, transmit and use information. Information technology is also often referred to as information and communication technology. It mainly includes sensing technology, computer and intelligence technology, communication technology and control technology. 


\subsection{Development Process of Informatization}

\subsubsection{The Origin of Informatization}

Information technology is based on modern communication, network, database and other technologies. It is a technology that collects the data of each element of the research object into the database for specific people to live, work, learn, and assist in decisionmaking. By using this technology, it can greatly improve the efficiency of various behaviors, reduce costs, and provide great technical support for promoting the progress of human society.

Informatization first appeared in the academic literature of Japan in the 1960s, mainly explained and confined from the perspective of industry. In the 1970s, Germany, UNESCO and other countries and international organizations have issued a series of plans to boost the application and development of information technology in society. In these plans, information infrastructure is one of the most important links.

\subsubsection{Us Information Superhighway Program}

In 1993, the U.S. government formally advanced the national information infrastructure, which is commonly known as the information superhighway plan. The core of the plan is to develop a comprehensive information service system with the Internet as the core and accelerate the application of information technology in various social fields. Subsequently, many developed and developing countries have took up a series of national information infrastructure construction program, which set off a wave of global information construction.

\subsubsection{Application of Information Technology in Education}

With the implementation of the information superhighway plan, the information superhighway plan of the United States takes the application of information technology as an important way of education reform facing the 21 st century. This practice of the United States has aroused strong repercussions from various countries in the world, and many governments have formulated plans to promote the application of information technology in education. In the late 1990s, with the rapid development of network technology, the Chinese government put forward the concept of education informatization, and gradually applied information technology to education.

\section{THE INFLUENCE OF INFORMATION TECHNOLOGY ON EDUCATION}

\subsection{Definition of Education}

The word "education" comes from the book of Mencius "to get the world's talents and educate them". In a broad sense, education refers to the social practice activities that affect people's physical and mental development. The Latin "Educare" is the source of education, which means to lead out. Education has at least three functions: the first is to impart knowledge, the second is to form a way of thinking, and the third is to improve quality.

\subsection{The Influence of Information Technology on Information Storage and Utilization}

\subsubsection{Information Technology Greatly Improves Information Storage Capacity}

In the final analysis, knowledge is a kind of information. The storage of human information has experienced tortoise shells, animal bones, bamboo slips, paper, disks and computers. Information storage is an activity of storing processed and ordered information in a specific carrier according to a certain format and order. The purpose of information storage is to facilitate people to quickly and accurately identify, locate and retrieve information. Without information storage, we can not make full use of the collected and processed information. Information technology greatly improves the storage capacity of information. A 100g hard disk can store the same amount of information off five million books, equivalent to the collection of a large library.

\subsubsection{Analysis and Processing of Information By Information Technology to Enhance the Value of Information}

Modern information technology is used to analyze and process the stored information and data, and to deeply mine the inherent information and core value. Information technology makes information a valuable natural resource.

In 2013, the scale of the global digital world will reach $3.5 \mathrm{zb}$, and by 2020 , the global data volume will increase to $44 \mathrm{zb}$. In terms of quantity, $44 \mathrm{zb}$ is equivalent to 62.7 times of sand on all beaches in the world. Human beings have entered a big data era of deep mining of internal information and core value of data. "Big data", a seemingly simple and straightforward term, is leading a new wave of technological and conceptual innovation in the world. Thomas H. Davenport, visiting professor of Harvard Business School, pointed out: "data and its differentiation will change the business functions of every industry in the next decade. If we start to work on 
big data earlier, any organization can gain obvious competitive advantage. "

\subsection{Information Technology and Educational Resources Sharing}

\subsubsection{Information Technology Promotes the Development and Sharing of Educational Resources}

The idea of using information technology to promote global knowledge opening and sharing originated from the open courseware project launched by MIT in 2001. In order to promote the further development of the project, UNESCO put forward the concept of open education resources, that is "hope to jointly develop universal education resources for the use of all mankind". Then the concept and practice of open education resources attracted wide attention all over the world. Knowledge is the common wealth of human beings. Free and open access to educational opportunities is a basic right of human beings. The construction of open educational resources can make ordinary people free and open access to rich and high-quality learning resources, and promote the fairness and democratization of education to a certain extent.

The combination of the rapid growth of Internet and the expansion of open education resources has a revolutionary prospect. The course videos of "ted-ed" in Ted (technology, entertainment, design) education column, the micro videos of Khan Academy and the large-scale open online courses are of far-reaching significance to promote global knowledge sharing. In 2003, China established the China Open Education Resources Association and started the construction project of excellent video courses; in 2010, Netease, Sina and other media launched the project of global famous schools\&apos; video open courses; in 2011, China started the construction project of national excellent open courses, and the first batch of 20 "Chinese University video open Courses" were open to the public free of charge; in 2013, Tsinghua University and Peking University joined EDX and coursera This development track also shows China\&apos;s positive action in the context of oer movement.

\subsubsection{Information Technology Makes the}

\section{Sharing of Educational Resources not Limited by} Time and Space

Lifelong learning and all-round learning define people\&apos;s learning and life structure from time dimension and space dimension. The former emphasizes that learning is a continuous activity throughout ones life, while the latter points out that there are different ways of learning, including formal learning and informal learning. Information technology has changed the space- time structure of human activities, which means that people can learn through a variety of channels at any time and any place, and the acquisition of knowledge is no longer limited to school education. Access to information and educational resources anytimre through mobile network terminals such as mobile phones. Different from the previous school classrooe and anywhem, the educated enjoy the same educational resources without the limitation of time and space.

\subsubsection{The Influence of Information Technology on the Cost of Obtaining Information}

Information technology makes the time cost for the educated to obtain information lower, because education is mainly a kind of transmission of information, which may be knowledge or a way of thinking, and can be transmitted through information technology. Because the educatee saves the time to and from the school, it can be quickly realized through the mobile network terminal, thus greatly saving the time cost of the educatee.

Information technology reduces the cost of obtaining information through the following aspects. The Internet makes a lot of knowledge more accessible. A lot of information access is almost zero cost. The government and relevant educational institutions provide free educational resources such as MOOCS, which can be directly obtained free of charge on the Internet.

\subsection{The Impact of Information Technology on Educational Interactivity}

In 1998, former Vice President Al Gore of the United States put forward the concept of "Digital Earth". Since then, the world has accepted the concept of digitalization, leading to the concepts of digital city and digital campus. In 2008, Peng Mingsheng, President of IBM in the United States, put forward the concept of "smart earth", and then gave birth to new concepts such as smart city and smart education.

Through the integration of learning terminal, wireless network, multi screen interaction, natural interaction and other technologies to provide intelligent interactive learning space for learners, based on the project-based learning process to highlight the support for the wisdom development of classroom teaching activities.

\section{CONCLUSION}

With the promotion of big data, artificial intelligence and other intelligent information technology, education is undergoing profound changes, and finally the construction of a new pattern. The influence of information technology on various industries is profound, comprehensive and irresistible. To strengthen the construction of education informatization is the commanding point for all countries and governments to 
seize the development of education. How to make full use of information technology for information storage, information analysis and processing, development and sharing of educational resources and the interaction of smart education is an important issue for all countries and governments.

\section{REFERENCES}

[1] Zhou Nanzhao, etc. Regional Guidelines for Teacher Development for Pedagogy-Technology Integration [M]. Bangkok: UNESCO Asia and Pacific Regional Bureau for Education. Thailand, 2004.

[2] The Open University Among Top-rated Universities for Student Satisfaction for 9th Year Running[EB/OL].

http://www3.open.ac.uk.2013.8.13.

[3] Jonathan Bergman, Aaron Sams. Flip Your Classroom: Reach Every Student in Every Class Every Day[M]. ISTE\&ASCD.3-5.

[4] ISTE Standard $\cdot \mathrm{T}[\mathrm{EB} / \mathrm{OL}]$. http://www.iste.org/docs/pdfs/20-

14_ISTE_Standards-S_PDF.pdf.[4] Universities Reshaping Education on the Web[N]. The News York Times, 2012-07-20.

[5] Education Site Expand Slate of Universities and Courses[N]. The News York Times, 2012-10-09.

[6] A Survey on MOOC Providers for Higher Education[J]. International Journal of Management \& Information Technology, 2013, 7(01). 